\title{
Evaluating Hydrological Model Performances on Stream Flow Simulation with Agricultural Management
}

\author{
Xiaojing Ni, Prem B. Parajuli* \\ Agricultural and Biological Engineering, Mississippi State University \\ 130 Creelman St., Mail Box 9632, Mississippi State, MS, 39762, U.S.A. \\ *E-mail: pparajuli@abe.msstate.edu
}

\begin{abstract}
Two comprehensive agricultural watershed-scale hydrological models: Soil and Water Assessment Tool (SWAT), and Annualized Agricultural Non-Point Source Pollution Model (AnnAGNPS), have been widely used for evaluating agricultural Best Management Practice (BMP). In this study, models were developed for the Big Sunflower River Watershed (BSRW) in Mississippi, USA. Both hydrological models were successfully calibrated and validated for predicting monthly stream flow discharges from three USGS gages (Merigold, Sunflower, and Leland) within the BSRW. The model performances were reasonable with $\mathrm{R}^{2}$ and NSE values range from 0.45 to 0.84 for SWAT, and from 0.34 to 0.66 for AnnAGNPS. Both models predicted lower stream flow discharge with conservation tillage practice as compare to conventional tillage practice BMP evaluated in this study. Overall, results showed that both SWAT and AnnAGNPS models successfully simulated hydrological conditions of the watershed with agricultural BMP, and these models can be useful for making hydrological decisions related to agricultural watershed managements.
\end{abstract}

Keywords: SWAT, AnnAGNPS, tillage, streamflow, hydrology, BMP

DOI: $10.7176 / \mathrm{JEP} / 12-3-03$

Publication date: January $31^{\text {st }} 2021$

\section{Introduction}

With greater understanding of watershed hydrology, various modeling tools were developed to simulate watershed hydrological processes. Watershed models have their emphasis on different aspects of watershed representation such as TR-55 (NRCS, 1986) and TR-20 developed by Natural Resources Conservation Service (NRCS) are common watershed runoff models for single event focusing on small urban or urbanizing watershed. Hydrologic Modeling System (HEC-HMS - Feldman, 2000) developed by the United States Army Corps of Engineers Hydrologic Engineering Center is a runoff simulating tool with several options including continuous simulation. Agricultural activities such as intensive fertilization and tillage operation could have great influences on surface water quality as well as water quantity (Ayers \& Westcot, 1985; Shipitalo \& Edwards, 1998; Vaché et al., 2002). Agricultural Best Management Practices (BMPs), as solutions helping reduce the negative impacts of crop production, have been widely implemented in United States. In order to evaluate BMPs impacts on watershed processes, watershed simulation with BMP scenarios have considered as an effective approach (Arnold et al., 1993; Arabi et al., 2008). The selected simulating tool need to account for both hydrologic and agricultural activities during simulation.

Within various modeling tools, there are two modeling tools fulfilling the requirements have the most applications in U.S. The first one, Soil and Water Assessment Tool (SWAT), a process-based watershed-modeling tool, allows simulating agricultural activities such as agricultural tillage operation and crop rotation (Ullrich \& Volk, 2009; Kirsch et al., 2002). Previous studies have demonstrated the abilities of SWAT model to assess impacts of agricultural activities on surface water quality and quantity (Kirsch et al., 2002; Arabi et al., 2008; Neitsch et al. 2011). Another one is Annualized Agricultural Non-Point Source Pollution Model (AnnAGNPS). It is a userfriendly watershed-modeling tool emphasizing on agricultural area, which also contains modules simulating BMPs such as conservation tillage and crop rotation scenarios (Yuan et al., 2001; Srivastava et al., 2002; Bingner et al., 2015).

Performances of different watershed models on hydrology simulations have been compared by some previous studies. Van Liew et al. (2003) compared the performance of HSPF and SWAT on runoff simulation in an agricultural watershed. They compared HSPF and SWAT model performances predicting various time-scale stream flows using standard statistical parameters such as deviation and coefficient of efficiency. They reported that the SWAT model was a more robust tool than HSPF in their study. Nasr et al. (2007) compared SWAT, HSPF, and Systeme Hydrologique Europeen TRANsport (SHETRAN) model efficiency in predicting phosphorus yield by comparing model results with observed data. They recommended the SWAT model as a good tool to estimate phosphorus yield. Parajuli et al. (2009) compared the performances of SWAT and AnnAGNPS using various statistical parameters including coefficient of determination $\left(\mathrm{R}^{2}\right)$, and Nash-Sutcliffe model efficiency coefficient (NSE). They also summarized the differences in methods used to simulate same physical process in two models. Both models had fair to good performances simulating stream flow and sediment yield. All of these previous 
studies were mainly focused on comparing the performance among models. Performances of different models indicate the ability to simulate watershed condition, which is important for choosing appropriate models for a specific watershed application. After selecting an appropriate model for a specific application, making decisions based on the scenario simulations is the next step. Thus, the evaluations of the results of concerned scenarios from different models are necessary. Thus, the specific objectives of this study included: (i) evaluating models performance for predicting stream flow discharges, and (ii) comparing models for simulating stream flow discharge with tillage practices.

\section{Methodology}

2.1 Model parameters

The Big Sunflower River Watershed (BSRW, Fig. 1) was the target watershed in this study located in Mississippi with crop production as mainstay of its economy (Parajuli \& Jayakody, 2012). The watershed contains approximately $80 \%$ croplands, $15 \%$ of forest, and other land use areas (USDA/NASS, 2016). With the agricultural water use as the main concern in simulation, to ensure that two hydrological models (SWAT and AnnAGNPS) were comparable, the same input data including both for hydrology simulation and agricultural management practices were applied in both models. The watershed simulation data include Digital Elevation Model (DEM) (USGS, 1999), SSURGO soil type (USDA, 2005), Crop Data Layer (CDL - USDA/NASS, 2016) for land use and cover, and climate information from Climate Forecast System Reanalysis (CFSR) database (NCDC, 2016) and Global Historical Climatology Network (GHCN) - daily database (NOAA, 2016). The general crop management practices in the watershed were generated based on previous publication (Parajuli et al., 2013); and on-site annual crop trial reports (MAFES, 2000-2014).

There are similar methodologies used in both models to describe physical modeling procedures. Both models used original or revised version of the Soil Conservation Service (SCS) curve number (SCS, 1985) based method to simulate surface runoff (King et al., 1999; Parajuli et al., 2009); and Universal Soil Loss Equation (USLE Wischmeier \& Smith, 1978) based method to simulate sediment yield (Borah \& Bera, 2003; Parajuli et al., 2009). Thus, the curve number and USLE method related factors were kept consistent in both models.

\subsection{SWAT model}

Soil and Water Assessment Tool (SWAT) is a physical-based hydrological and water quality model (Arnold et al., 1993). It allows predicting impacts of agricultural management practices (e.g. short-term, long-term) on stream water quantity and quality in large and complex watershed. Moreover, it considers spatial parameters, such as soil type and land use and cover, as semi-distributed, thus, provides high computational efficiency using various mathematical equations to describe each hydrological process in hydrological response unit (HRU). HRU as the unit of simulation is defined by variation of surface elevation, land use and cover, and soil type (Neitsch et al., 2011). In addition, the model is designed to be user-friendly with readily available input data (e.g. surface elevation, land use and cover, soil type, weather). After initial introduction during 1980's, it has been continuously developed, which helped to improve the estimation under various locations (e.g. freezing region, high elevation region), specific agricultural management practices (e.g. tile drainage), and with the change of climate and land use.

In this study, the BSRW was divided into 1,799 HRUs with 22 sub-basins based on spatial variation of soil type, land use and cover, and surface elevation (Fig. 1). The threshold area values of 5\% for soil type, $1 \%$ for land use, and $5 \%$ for slope length of each sub-basin area were used to define HRU. Calibration process included both auto and manual calibration. SWAT-Cup SUFI2 algorithm was applied to obtain simulation with highest R2 and NSE values by comparing the simulated model results and observations at the USGS gaging stations. This study utilized monthly stream flow data from 2008 to 2015. Afterward, SCS curve number was manually calibrated.

\subsection{AnnAGNPS model}

Annualized Agricultural Non-point Source model (AnnAGNPS) is a process-based, watershed scale, continuous time pollutant-loading model that focus on agricultural watershed (Binger et al., 2018). The AnnAGNPS model utilizes surface elevation, land use, soil type, weather information, and pollution input type data for each spatial modeling unit of the watershed to quantify fate and transport process of non-point source loads (e.g. pesticide, sediment, and nutrient). The AnnAGNPS model provide emphasis on combining various simulating modules including upstream agricultural management practices (e. g. irrigation, tile drainage, tillage); and hydrological processes (e. g. surface runoff, subsurface flow) to demonstrate the impact of pollutant sources on stream water quality. The AnnAGNPS model has been available or developed during 1980's. Recent updates of the AnnAGNPS model are focused on additional features including gully erosion simulation to improve overall model performances.

In this study, the BSRW was divided into 193 cells as the modeling units in the subsequent simulation in AnnAGNPS model, based on surface elevation by TopAGNPS module (Fig. 1). The spatial data including soil type, weather stations and land use and cover were summarized and utilized similar to the SWAT model to the 
AnnAGNPS cells. The manual calibration was performed for AnnAGNPS model.

\subsection{Tillage management scenarios}

In this study, two tillage management scenarios namely conventional and conservation tillage management practices were simulated using SWAT and AnnAGNPS models. Tillage operation affects surface water runoff (Shipitalo et al., 1998) and water quality including nitrogen, phosphorus, and sediment (Tan et al., 2002; Vaché et al., 2002). Conventional tillage practice was applied in about $70 \%$ of the area of Mississippi Delta region (Snipes et al., 2005), while conservation tillage is a commonly implemented BMP in U.S to prevent soil erosion. Thus, the baseline scenario was with conventional tillage, while conservation tillage management was considered as a BMP scenario. In both model, SCS curve number was considered as the parameter distinguishing conventional and conservation tillage management scenarios (Kirsch et al., 2002). In addition, its value was based on soil type and land use combination, which was set based on previous study by Ni and Parajuli (2018).

\subsection{Model calibration and validation}

Both SWAT and AnnAGNPS models were calibrated and validated by monthly stream flow discharge from USGS gages. Models were calibrated using monthly stream flow discharge from Merigold station, while validated at Sunflower and Leland gages. The $\mathrm{R}^{2}$ and NSE values were used to evaluate each model performance (Parajuli, 2012; Kim and Parajuli, 2014).

\section{Results and Discussion}

\subsection{Calibration and validation}

The SWAT and AnnAGNPS models calibration results for stream flow showed reasonable performance based on $\mathrm{R}^{2}$ and NSE values (Moriasi et al., 2015; Table 1). The SWAT model showed higher $\mathrm{R}^{2}$ and similar NSE value when compared to AnnAGNPS. The similar results were expected since both models used SCS curve number (SCS, 1985) based methods to estimate surface runoff (Bingner et al., 2015; Neitsch et al., 2011).

The SWAT and AnnAGNPS models simulated monthly stream flows were compared with the observed monthly stream flow at Sunflower gage station (Fig. 2). The model simulated average monthly stream flows were $38.9 \mathrm{cms}$ by SWAT, $29.1 \mathrm{cms}$ by AnnAGNPS, and $28.5 \mathrm{cms}$ by observation. The $\mathrm{R}^{2}$ values in SWAT simulation were higher than AnnAGNPS, while NSE values were similar. With using same curve number, homogeneous modeling units, same land use, and soil type in both models, the differences might be resulted from the different modifications of SCS curve number methods used to simulate surface runoff in the SWAT and AnnAGNPS models. The AnnAGNPS model considered the retention parameter that is an important parameter in SCS curve number method varies with soil moisture content, while SWAT model considered the retention parameter varies with plant potential evapotranspiration in addition to soil moisture content (Bingner et al., 2015; Neitsch et al., 2011).

\subsection{BMP Scenarios comparison}

In order to obtain comparable results for the BMP scenarios simulated using SWAT and AnnAGNPS models, the comparison were conducted at three USGS gaging stations, where the baseline scenario was compared with observed stream flow data during calibration and validation processes. Fig. 3 shows the scenario comparisons between conventional tillage and conservational tillage using SWAT and AnnAGNPS models at three USGS gaging stations. The change variation among three stations were small with average reduction of monthly stream flow of $43 \%, 42 \%$ and $32 \%$ for Merigold, Sunflower and Leland respectively by using the AnnAGNPS model, and $12 \%, 11 \%$ and $13 \%$ by using the SWAT model. Both models showed the reduction of stream flow in conservational tillage as compare to conventional tillage. The stream flow was more sensitive to curve number in the AnnAGNPS model than in the SWAT model. This might be caused from the difference between modeling units in two models. The modeling units in the AnnAGNPS model were dependent on the surface elevation, while the modeling units in the SWAT model were dependent on the combination of land use, soil type and slope length. The SCS curve number method calculates surface runoff by considering the different infiltration conditions of land cover, soil group and land treatment (SCS, 1985). Thus, the modeling units in the SWAT model were more compatible with the SCS curve number method. The AnnAGNPS model considers majority of land use and soil type as its modeling units, which may have caused that changing of curve numbers might be not be compatible with the tillage management occurring on the cropland.

\section{Conclusion}

Both the SWAT and the AnnAGNPS models determined acceptable stream flow simulation results during model calibration and validation processes with R2 and NSE values range from 0.45 to 0.84 for the SWAT, and from 0.34 to 0.66 for the AnnAGNPS. Despite similar inputs in the two hydrological models, simulated stream flow outputs were slightly varied with BMP scenarios due to different modifications of the SCS and USLE methods applied in the SWAT and the AnnAGNPS models. For tillage scenarios, both model showed the reduction of 
stream flow with conservational tillage scenario as compare to conventional tillage.

This research study resulted that both hydrological models have ability to simulate BMP such as tillage management practices at the watershed scales, but the modeler need to pay attention to the different response from different models. The SWAT and AnnAGNPS models have different sensitivities to the parameters and inputs, which modelers may need to understand while applying model for the hydrological investigations.

\section{Acknowledgements:}

We would like to acknowledge the financial support of AFRI competitive grant award \# 2013-67020-21407, and 2017-67020-26375, from the USDA/NIFA for this project. We would like to acknowledge the support of Yazoo Mississippi Delta Joint Water Management District; USGS; and all the collaborators.

\section{References}

Arabi, M., Frankenberger, J. R., Engel, B. A., \& Arnold, J. G. (2008). Representation of agricultural conservation practices with SWAT. Hydrological Processes 22(16), 3042-3055, https://doi.org/10.1002/hyp.6890

Arnold, J. G., Allen, P. M., \& Bernhardt, G. (1993). A comprehensive surface-groundwater flow model. Journal of Hydrology 142(1-4), 47-69.

Ayers, R. S., \& Westcot, D. W. (1985). Water quality for agriculture Vol. 29. Rome: Food and Agriculture Organization of the United Nations.

Bingner, R.L., Theurer, F.D., \& Yuan, Y. (2015). AnnAGNPS technical processes. USDA-ARS. National Sedimentation Laboratory.

Bingner, R. L., Theurer, F. D., \& Yuan, Y. (2018). AnnAGNPS technical processes: Documentation version 5.5. USDA-ARS National Sedimentation Laboratory, Oxford, Mississippi, U.S.A.

Borah, D. K., \& Bera, M. (2003). Watershed-scale hydrologic and nonpoint-source pollution models: Review of mathematical bases. Transactions of the ASAE 46(6), 1553-1566, https://doi.org/10.13031/2013.15644

Feldman, A. D. (2000). Hydrologic modeling system HEC-HMS: technical reference manual. U.S. Army Corps of Engineers, Hydrologic Engineering Center.

Feyereisen, G. W., Strickland, T. C., Bosch, D. D., Truman, C. C., Sheridan, J. M., \& Potter, T. L. (2008). Curve number estimates for conventional and conservation tillages in the southeastern Coastal Plain. Journal of Soil and Water Conservation 63(3), 120-128, https://doi.org/10.2489/jswc.63.3.120

Kim, H.K., Parajuli, P.B., (2014). Impacts of reservoir outflow estimation methods in SWAT model calibration. Transactions of the ASABE 57 (4), 1029-1042.

King, K. W., Arnold, J. G., \& Bingner, R. L.(1999). Comparison of Green-Ampt and curve number methods on Goodwin Creek watershed using SWAT. Transactions of the ASAE 42(4), 919-926, https://doi.org/10.13031/2013.13272

Kirsch, K., Kirsch, A., \& Arnold, J.G. (2002) Predicting sediment and phosphorus loads in the Rock River Basin using SWAT. Transactions of the ASAE 45(6), 1757-1769, https://doi.org/ 10.13031/2013.11427

Mississippi State Agricultural and Forest Experiment Station (MAFES) (2000-2014). Variety Trails Information Bulletins 373-520. Mississippi State University

Moriasi, D. N., Gitau, M. W., Pai, N., \& Daggupati, P. (2015). Hydrologic and water quality models: Performance measures and evaluation criteria. Transactions of the ASAE 58(6), 1763-1785, https://doi.org/ $10.13031 /$ trans.58.10715

Nasr, A., Bruen, M., Jordan, P., Moles, R., Kiely, G., \& Byrne, P. (2007). A comparison of SWAT, HSPF and SHETRAN/GOPC for modelling phosphorus export from three catchments in Ireland. Water Research 41(5), 1065-1073, https://doi.org/10.1016/j.watres.2006.11.026

National Climatic Data Center (NCDC) (2016). Locate weather observation station record. Available at: http://www.ncdc.noaa.gov/oa/climate/stationlocator.html (accessed on 07.12.2016).

National Oceanic and Atmospheric Administration (NOAA) - National Centers for Environmental Information. (2016). Global Historical Climatology Network (GHCN) - Daily. Available at: https://www.ncdc.noaa.gov/cdo-web/search?datasetid=GHCND (accessed on 7.24.2017).

Neitsch, S. L., Arnold, J. G., Kiniry, J. R., \& Williams, J. R. (2011). Soil and water assessment tool theoretical documentation version 2009. Texas Water Resources Institute, Texas, U.S.A.

Ni, X., \& Parajuli, P. B. (2018). Evaluation of the impacts of BMPs and tailwater recovery system on surface and groundwater using satellite imagery and SWAT reservoir function. Agricultural Water Management 210, 7887.

NRCS. (1986). Urban Hydrology for Small Watersheds TR-55. USDA National Resource Conservation Service, Conservation Engineering Division Technology Release 55.

Parajuli, P.B., (2012). Evaluation of spatial variability on hydrology and nutrient source loads at watershed scale using a modeling approach. Hydrological Research 43 (6), 808-821.

Parajuli, P.B. \& Jayakody, P. (2012). Big Sunflower River Watershed Assessment: Preliminary Report. Office of 
Agricultural Communications, Mississippi State University.

Parajuli, P. B., Jayakody, P., Sassenrath, G. F., Ouyang, Y., \& Pote, J. W. (2013). Assessing the impacts of croprotation and tillage on crop yields and sediment yield using a modeling approach. Agricultural Water Management 119, 32-42, https://doi.org/10.1016/j.agwat.2012.12.010

Parajuli, P. B., Nelson, N. O., Frees, L. D., \& Mankin, K. R. (2009). Comparison of AnnAGNPS and SWAT model simulation results in USDA-CEAP agricultural watersheds in south-central Kansas. Hydrological Processes 23(5), 748-763, https://doi.org/10.1002/hyp.7174

Shipitalo, M. J., \& Edwards, W. M. (1998). Runoff and erosion control with conservation tillage and reducedinput practices on cropped watersheds. Soil and Tillage Research 46(1-2), 1-12, https://doi.org/10.1016/S0167-1987

Snipes, C.E., Nichols, S.P., Poston, D.H., Walker, T.W., Evans, L.P. \& Robinson, H.R. (2005). Current agricultural practices of the Mississippi Delta. Mississippi Agricultural and Forestry Experiment Station (MAFES)

Soil Conservation Service (SCS) (1985). Section 4: Hydrology. National Engineering Handbook.

Srivastava, P., Hamlett, J. M., Robillard, P. D., \& Day, R. L. (2002). Watershed optimization of best management practices using AnnAGNPS and a genetic algorithm. Water Resources Research 38(3), 3-1, https://doi.org/10.1029/2001WR000365

Tan, C. S., Drury, C. F., Reynolds, W. D., Gaynor, J. D., Zhang, T. Q., \& Ng, H. Y. (2002). Effect of long-term conventional tillage and no-tillage systems on soil and water quality at the field scale. Water Science and Technology 46(6-7), 183-190, https://doi.org/10.2166/wst.2002.0678

Ullrich, A., \& Volk, M. (2009). Application of the Soil and Water Assessment Tool (SWAT) to predict the impact of alternative management practices on water quality and quantity. Agricultural Water Management 96(8), 1207-1217, https://doi.org/10.1016/j.agwat.2009.03.010

United States Department of Agriculture (USDA). (2005). Soil data mart. Natural Resources Conservation Service. Available at: http://soildatamart.nrcs.usda.gov/Default.aspx (accessed on 09.08.2014).

United States Department of Agriculture, National Agricultural Statistics Service (USDA/NASS). (2016). The Cropland Data Layer. Available at: http://www.nass.usda.gov/research/Cropland/SARS1a.htm (accessed 09.08.2014 and 03.09.2017).

United States Geological Society (USGS). National elevation dataset, 1999. Available at: http://seamless.usgs.gov/website/seamless/viewer.htm (accessed on 09.08.2014).

Vaché, K. B., Eilers, J. M., \& Santelmann, M. V. (2002). Water quality modeling of alternative agricultural scenarios in the us corn belt. Journal of the American Water Resources Association 38(3), 773-787, https://doi.org/10.1111/j.1752-1688.2002.tb00996.x

Van Liew, M. W., Arnold, J. G., \& Garbrecht, J. D. (2003). Hydrologic simulation on agricultural watersheds: Choosing between two models. Transactions of the ASAE 46(6), 1539-1551, https://doi.org/10.13031/2013.15643

Wischmeier, W. H., \& Smith, D. D. (1978). Predicting rainfall erosion losses-a guide to conservation planning. Washington, DC: USDA.

Yuan, Y., Bingner, R. L., \& Rebich, R. A. (2001). Evaluation of AnnAGNPS on Mississippi delta MSEA watersheds. Transactions of the ASAE 44(5), 1183-1190, https://doi.org/10.13031/2013.6448

Table 1. Stream flow calibration and validation performance for SWAT and AnnAGNPS models

\begin{tabular}{|l|l|l|l|l|}
\hline & SWAT & \multicolumn{2}{l|}{ AnnAGNPS } \\
\hline & $\mathrm{R}^{2}$ & $\mathrm{NSE}$ & $\mathrm{R}^{2}$ & $\mathrm{NSE}$ \\
\hline Calibration--Merigold & 0.69 & 0.64 & 0.53 & 0.51 \\
\hline Calibration--Sunflower & 0.65 & 0.45 & 0.57 & 0.51 \\
\hline Calibration--Leland & 0.73 & 0.61 & 0.59 & 0.54 \\
\hline Validation--Merigold & 0.68 & 0.50 & 0.57 & 0.55 \\
\hline Validation--Sunflower & 0.84 & 0.70 & 0.46 & 0.66 \\
\hline Validation--Leland & 0.70 & 0.46 & 0.48 & 0.34 \\
\hline
\end{tabular}



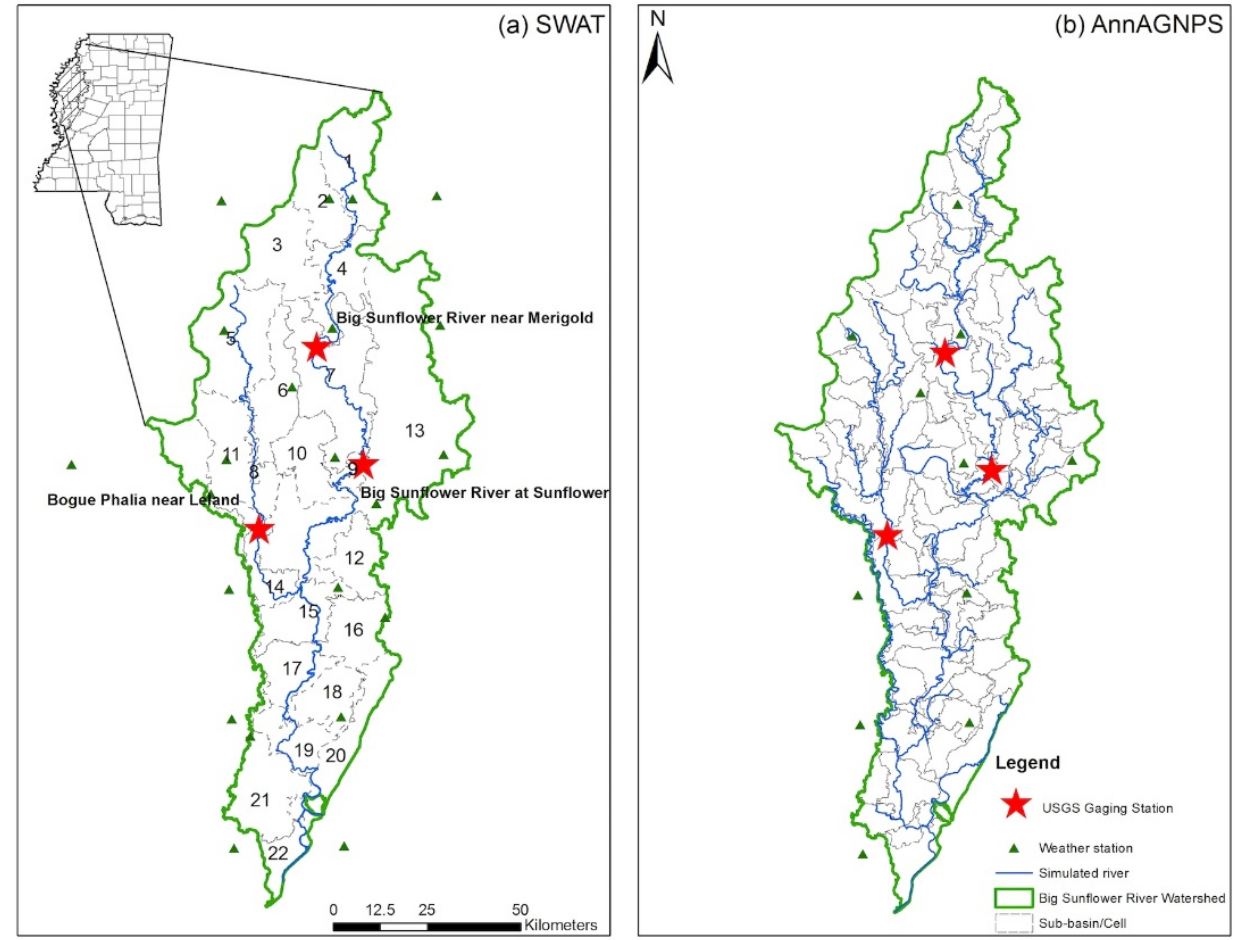

Figure 1. Location of watershed delineated by (a) SWAT, and (b) AnnAGNPS models with USGS gages and weather stations

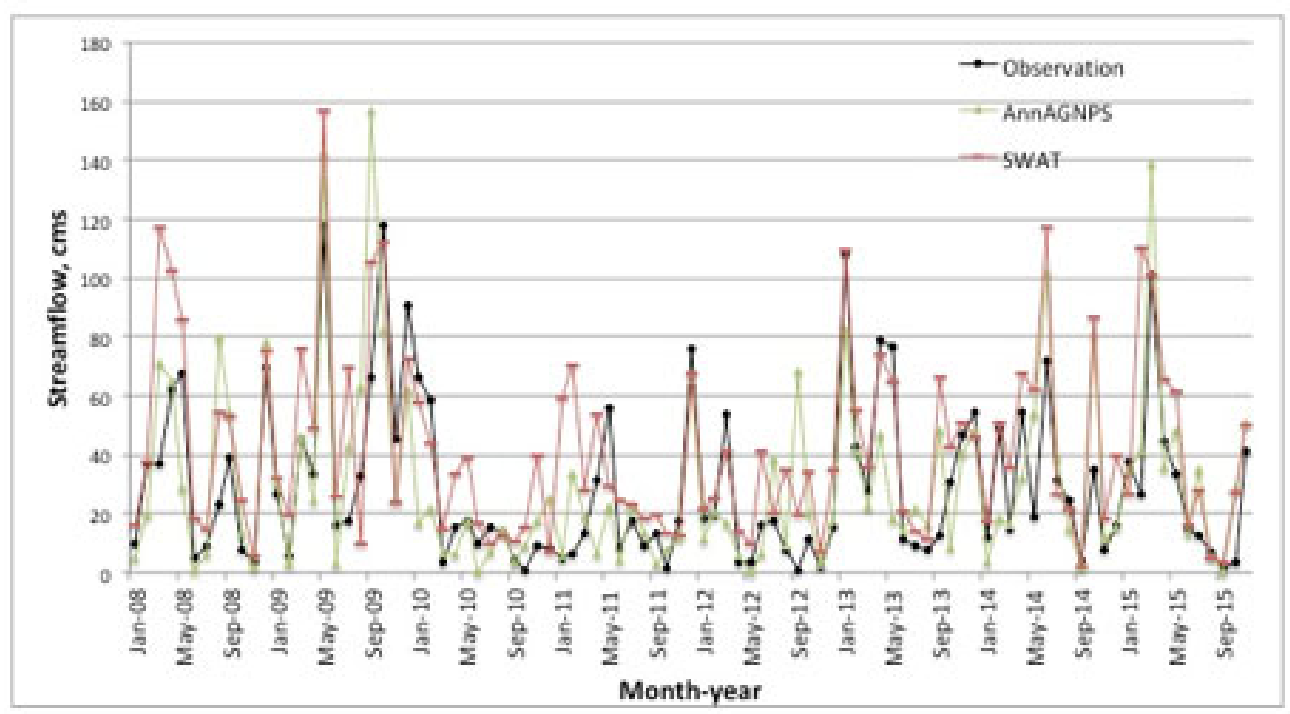

Figure 2. Stream flow predicted by SWAT and AnnAGNPS models as compared to observed data 

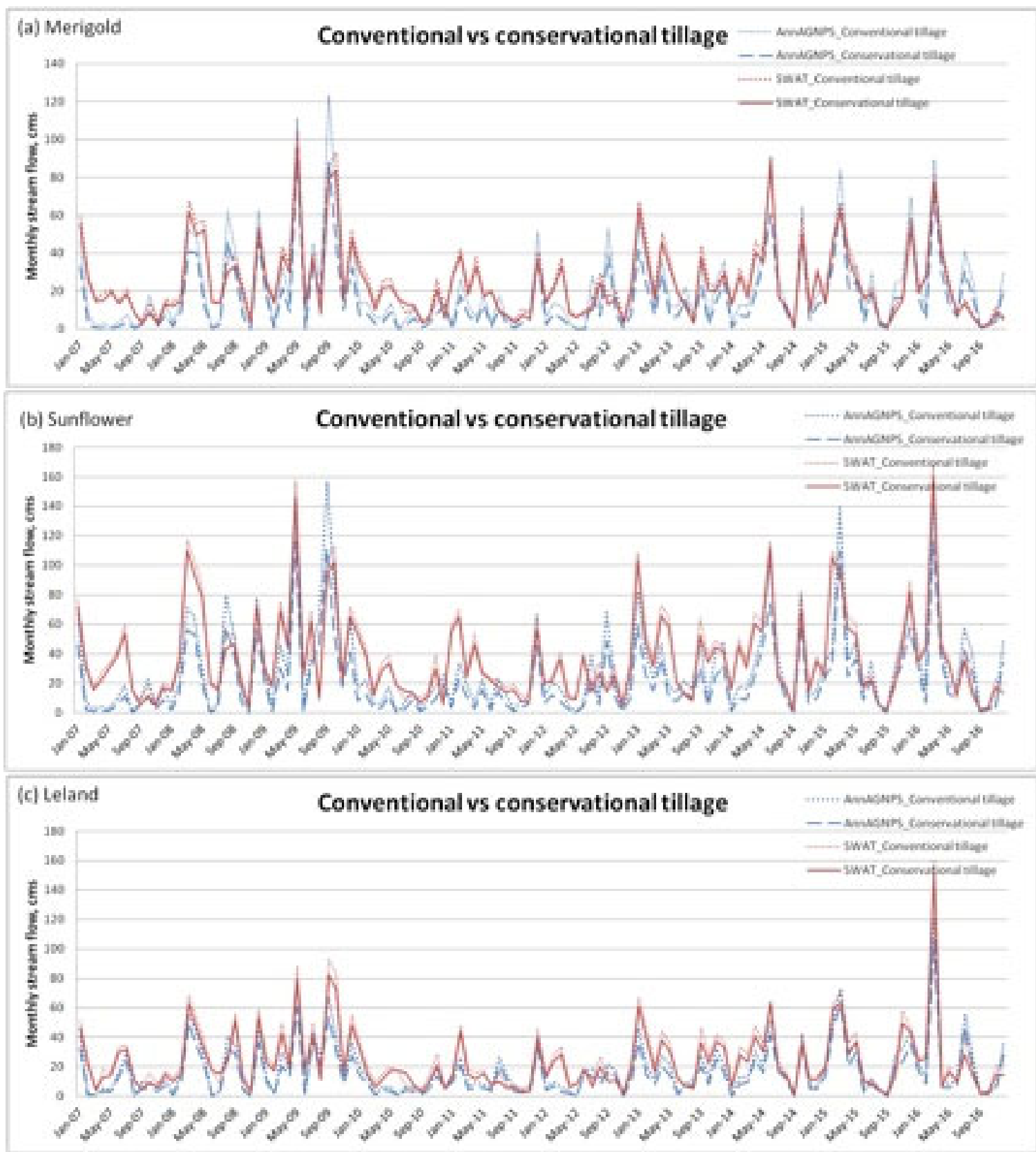

Figure 3. Conventional and conservational tillage stream flow simulated by SWAT and AnnAGNPS for: (a) Merigold (b) Sunflower, and (c) Leland gage stations. 